\title{
REPLY TO ARTHUR FRANKEL'S "COMMENT ON 'RUPTURE PROCESS OF THE 1987 SUPERSTITION HILLS EARTHQUAKE FROM THE INVERSION OF STRONG-MOTION DATA'"
}

\section{By David J. Wald, Stephen H. Hartzell, and Donald V. Helmberger}

We thank Art Frankel for his continuing interest in unraveling the details of the complicated source process of the 1987 Superstition Hills earthquake. His insightful comments and subsequent modeling on our part has helped to resolve some of the differences between the rupture model presented in Wald et al. (1990), hereafter referred to as WEA, and that published by Frankel and Wennerberg (1989), hereafter F\&W. The main issue raised by Frankel (1992) is the discrepancy between the two estimates for the location of high-frequency radiation during the third, largest subevent of this earthquake. According to Frankel's (1992) comment, the model of F\&W limits slip during subevent 3 to a zone less than $8 \mathrm{~km}$ long southeast of the hypocenter. Thus, the portion of the fault beginning at the fault step-over (Fig. 1) and southeast of that point did not generate high-frequency ground motions. The model WEA favor requires highfrequency radiation from both the northern segment of the fault (where F\&W require slip) as well as from the step-over region and the immediately adjacent southern fault segment. We agree that the clarification of this issue is extremely important considering that the link between high-frequency (damaging) strong motions and observations made at longer periods is often made to infer or estimate potential seismic hazards. Although we would like to resolve this issue definitively, we must be realistic and open to the possibility that the answer may be within the grey zone of resolution from this data set and our modeling sophistication, perhaps the very reason that there is a controversy at all.

Frankel's (1992) comment addresses three main observations: (1) the consistency of timing of observed subevent 3 arrivals at various azimuths, (2) the inability of the WEA model to match the timing of some subevent 3 arrivals, and (3) the possibility that station PTS pulls slip towards that station due to its proximity to the rupture area. We will first review some observations concerning the Superstition Hills earthquake, clarify a few attributes of both the F\&W and WEA models, and then, in turn, address each of the above issues. In addressing these issues, results of subsequent inversions prompted by this discussion will be presented.

There is no question as to whether or not slip occurred during this earthquake along the southern portion (southeast of fault step-over) of the Superstition Hills Fault. In fact, at the surface, co-seismic displacement was as great as it was north of the step-over (Sharp et al., 1989; Williams and Magistrale, 1989). Further, teleseismic studies that address the spatial distribution of the longer period energy release (Bent et al., 1989; Hwang et al., 1990) require greater than $10 \mathrm{~km}$ of separation between subevents 2 and 3 , placing the third subevent on the southern segment of the fault. In addition, geodetic inversions by Larson (1991) require nearly comparable dislocation on the northwest and southeast fault segments down to depths compatible with the WEA strong-motion inversion estimates. The question we are concerned with here is whether or not the strong-motion data require that high-frequency radiation occurred during the 


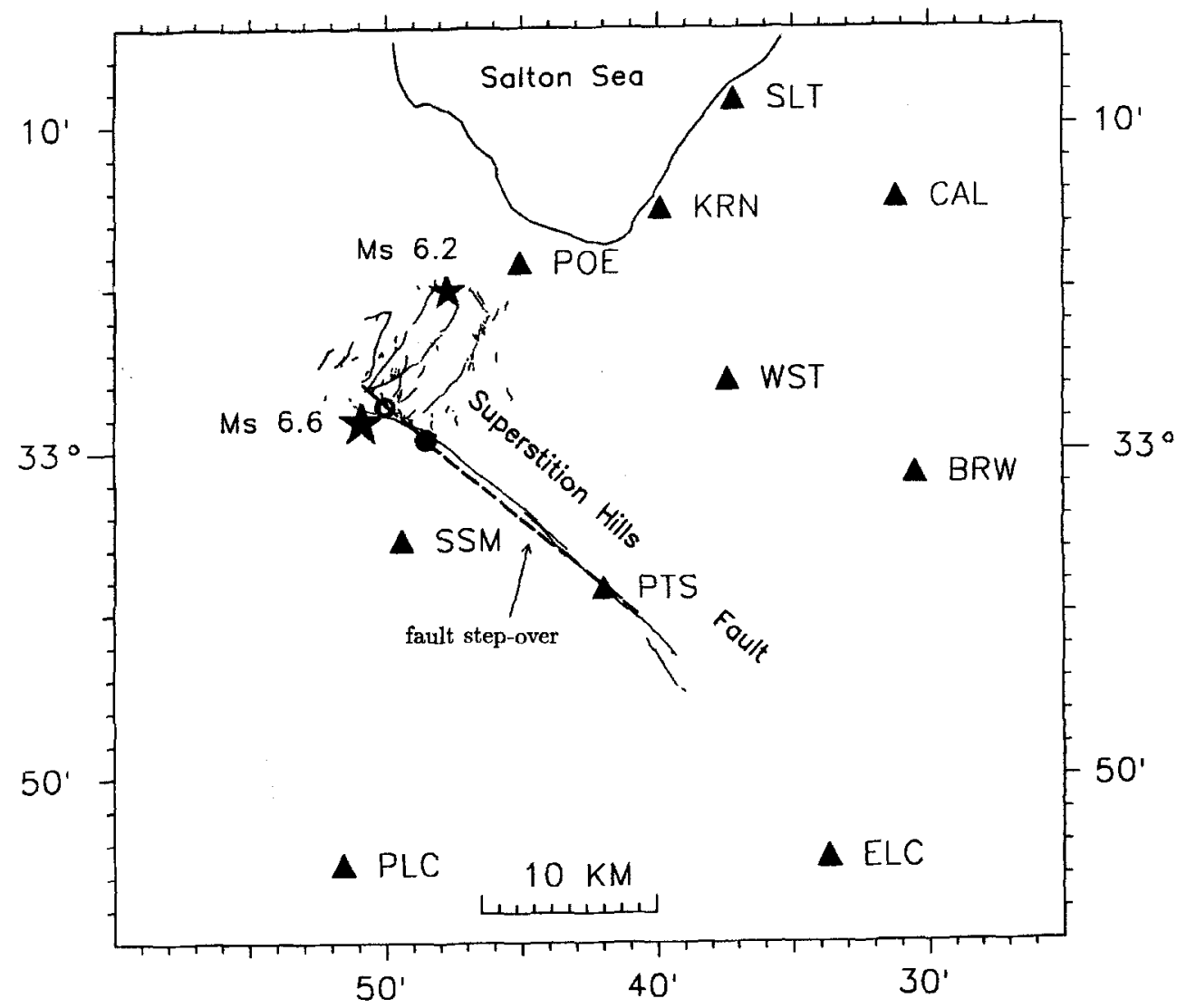

FIG. 1. Map of Superstition Hills area with strong-motion station locations (triangles). Location of WEA rupture hypocenter is shown with an open circle; the $F \& W$ hypocenter is shown as a filled circle. Note the location of the step-over in the surface trace of the Superstition Hills Fault.

third subevent in the step-over region and further southeastward along the fault, and what its relative contribution was compared with the northern half. Both strong-motion models estimate moment release at short periods $(5 \mathrm{sec}$ to 3 $\mathrm{Hz}$ ), that is, at least a factor of 2 lower than that determined at longer periods (greater than $10 \mathrm{sec}$ ). So there is a clear indication that some portion of the long-period slip is not seen in the local velocity observations. But do the strong-motion data alone require any slip in the distance range from 8 to $18 \mathrm{~km}$ southeast of the epicenter? In fact, both models require some slip well beyond 8 $\mathrm{km}$ southeast of the epicenter, but the relative proportions of the slip on the northern portion of the fault vary significantly.

Part of the controversy stems from difficulty in comparing the two models. First, note in Figure 1 that the hypocenter used by WEA (open circle) is $2.5 \mathrm{~km}$ northwest of that used by F\&W (filled circle). WEA use the fault projection of the epicenter from Magistrale et al. (1989), and F\&W use a location determined by picking arrivals on the strong motion records. Also notice that the WEA fault plane begins $4.5 \mathrm{~km}$ northwest of the initiation point of the $F \& W$ line source. We take exception to Frankel's (1992) representation of WEA subevent 3 as $3 \mathrm{~km}$ long (his Fig. 2), whereas WEA describe that subevent as a variable slip along an $18-\mathrm{km}$ rupture length. Only $25 \%$ of the total moment release from 

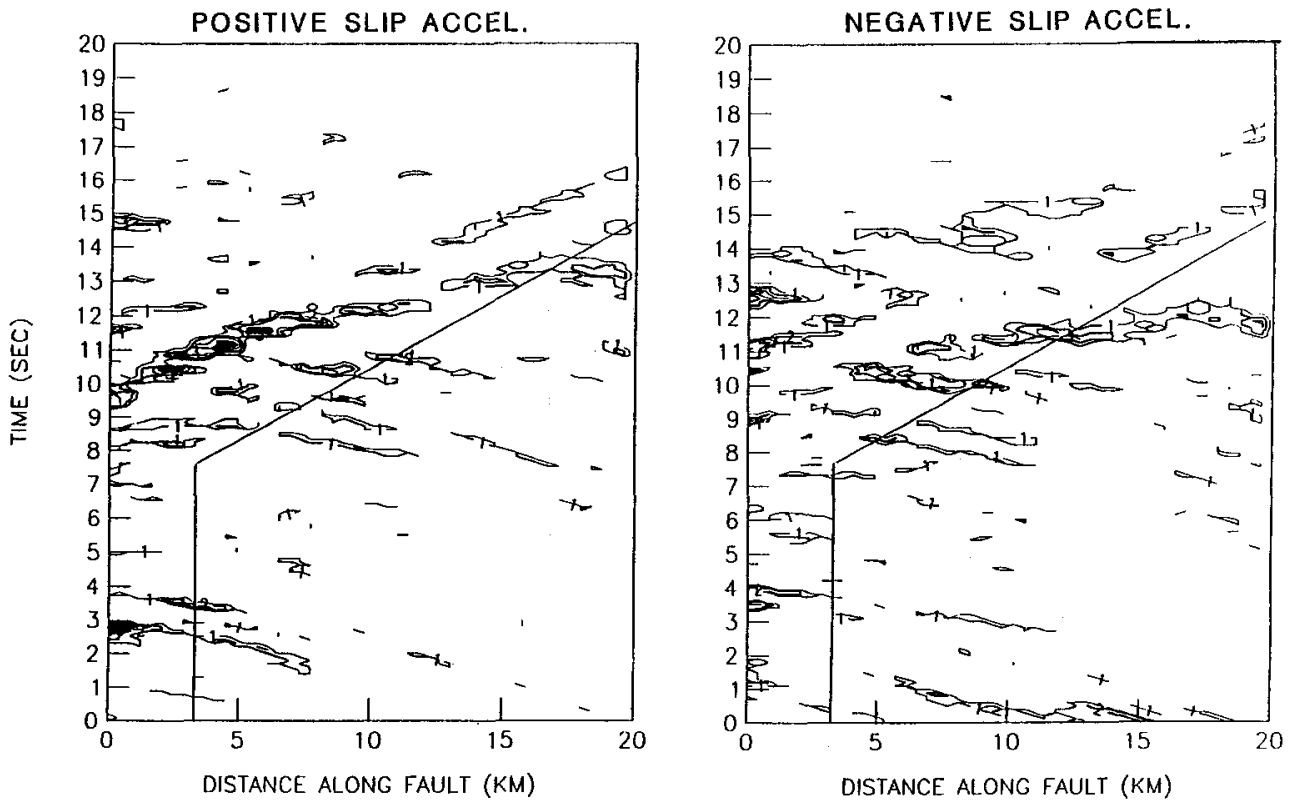

FIG. 2. Positive (left) and negative (right) slip accelerations (F\&W, Fig. 10c and d) of the preferred model of $F \& W$. Hypocenter is at $0 \mathrm{~km}$ distance along the fault. The surface fault step-over is located about $8 \mathrm{~km}$ along strike.

the WEA subevent 3 is from the region shown to represent that subevent in Figure 2 of Frankel (1992). In fact, the region northwest of the step-over contributes $56 \%$ of the subevent 3 moment release; $44 \%$ comes from the southeast. The WEA model, therefore, has as much moment release in the northwest as the F\&W model, and that feature of the rupture should not be disputed. Similarly, although the author states that slip in their model of subevent 3 is "located 0 to $8 \mathrm{~km}$ from the hypocenter," F\&W's preferred solution (their Fig. 10) has significant positive and negative slip accelerations out to about $17 \mathrm{~km}$. We show the positive and negative slip accelerations from their model in Figure 2. And, although they choose to ignore the slip beyond $8 \mathrm{~km}$ in their discussion, this slip must have contributed significantly to the fit between the data and the synthetics in their Figure 11. So again, these models are not as different as put forth by Frankel (1992).

Furthermore, when $F \& W$ use a line source at a depth of $5 \mathrm{~km}$, rather than at their 9-km preferred depth, the results (Fig. 3) require slip to be in the very region that our inversion shows slip and that Frankel (1992) suggests did not radiate high frequencies. They state: "there is an area of slip acceleration at $x=11 \mathrm{~km}$, and $t=13.5 \mathrm{sec}$ that was not apparent for the deeper source." Hence, it appears that a trade-off exists between the line source depth and the location of slip acceleration back-projected onto that line source, and therefore it may be inadequate for $\mathrm{F} \& \mathrm{~W}$ to describe what is undoubtably radiation from a 2-D fault with a 1-D model. Recall that rupture models for the 1979 Imperial Valley earthquake (e.g., Hartzell and Heaton, 1983), which occurred in a similar tectonic setting, had substantial slip distributed as shallow as $4 \mathrm{~km}$. As we have shown in Figure 4, both amplitudes and complexity of the Green's functions change significantly as a function of depth. F\&W use a delta function 
NW

F\&W Subevent 3

SE

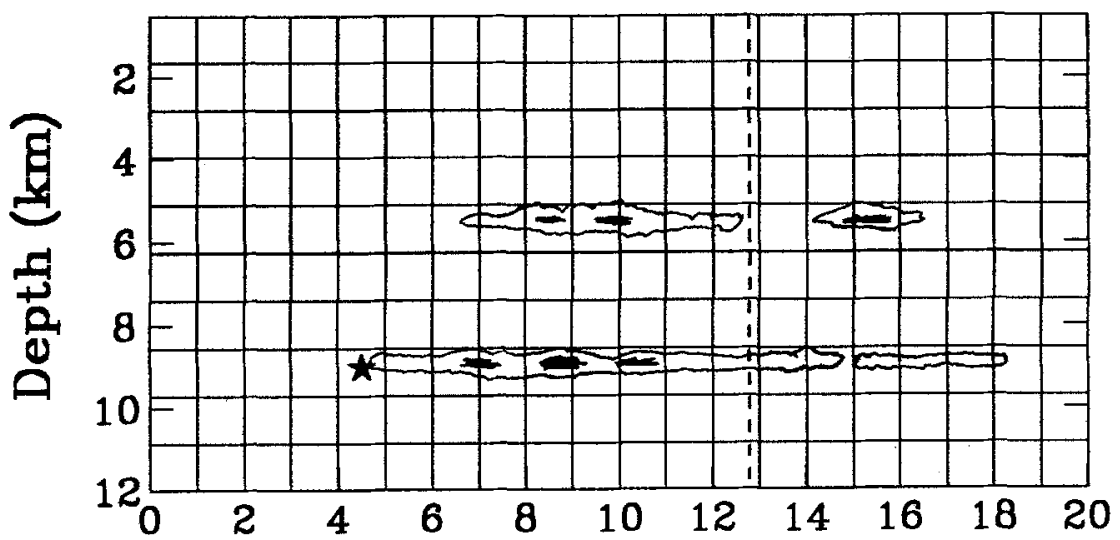

Wald et al. Subevent 3

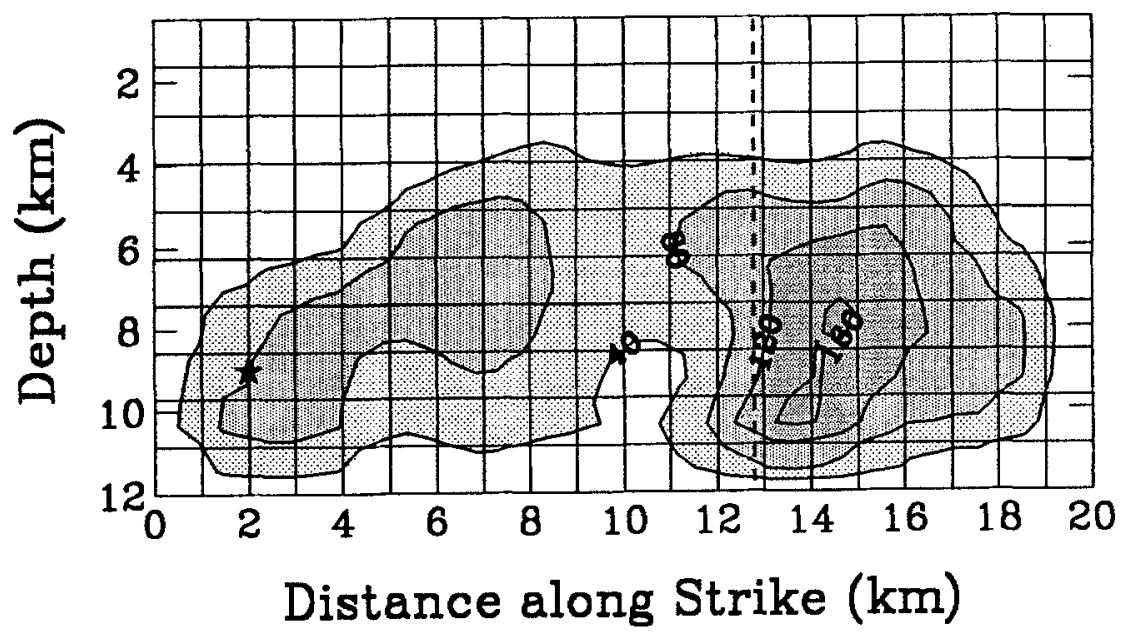

FIG. 3. Northwest-southeast cross section of the fault model showing subevent 3. Top figure shows F\&W line source for depths of 5 and $9 \mathrm{~km}$. The bottom figure is the subevent 3 of model 307 from WEA. Dashed lines indicates the fault step-over position at the ground surface.

in place of complete Green's functions used by WEA and shown in Figure 4. Note that while the direct $S H$ pulses are simple, as pointed out by F\&W, the $S V$ pulses are not. The later components display the well-known phase shifts and the development of higher-mode Rayleigh waves associated with the $(P-S V)$ coupled motions.

It is clear, however, that the relative high-frequency contributions over the extended length of subevent 3 differ between the F\&W and WEA models. We do not find this surprising. WEA have already noted that "a short delay $(8.1 \mathrm{sec})$ for subevent 3 allows the rupture to propagate to the southern section of the fault (Fig. 5, top). As the delay time increases to $8.6 \mathrm{sec}$, moment release is forced deeper (Fig. 5, middle). Finally, if delayed by $9.1 \mathrm{sec}$ (bottom of Fig. 5), 
$90^{\circ}$ Component

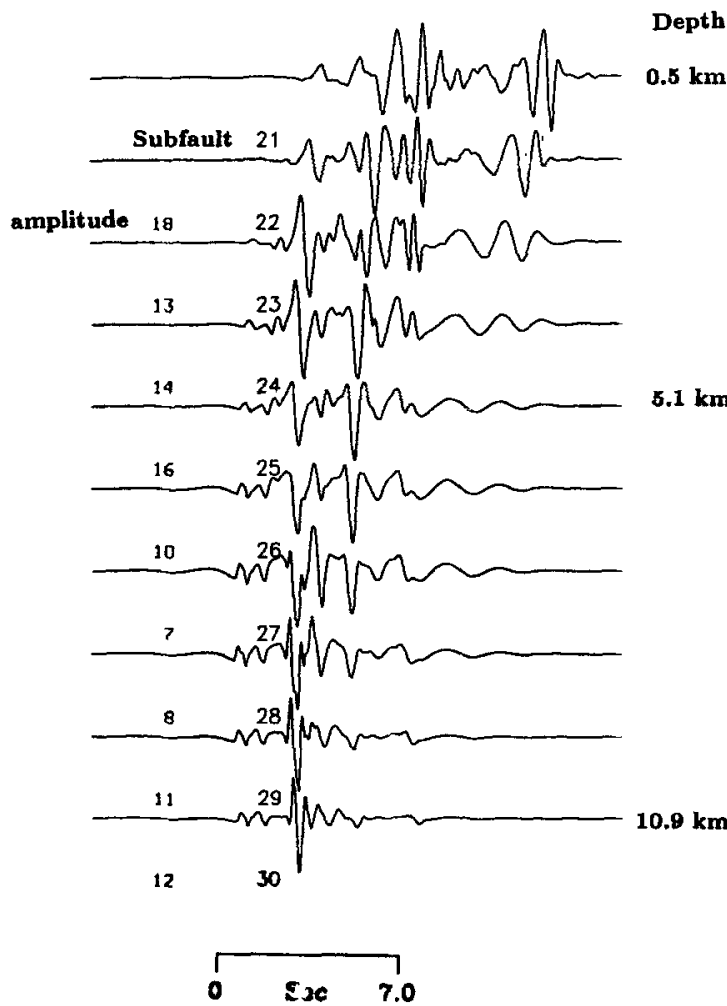

$180^{\circ}$ Component

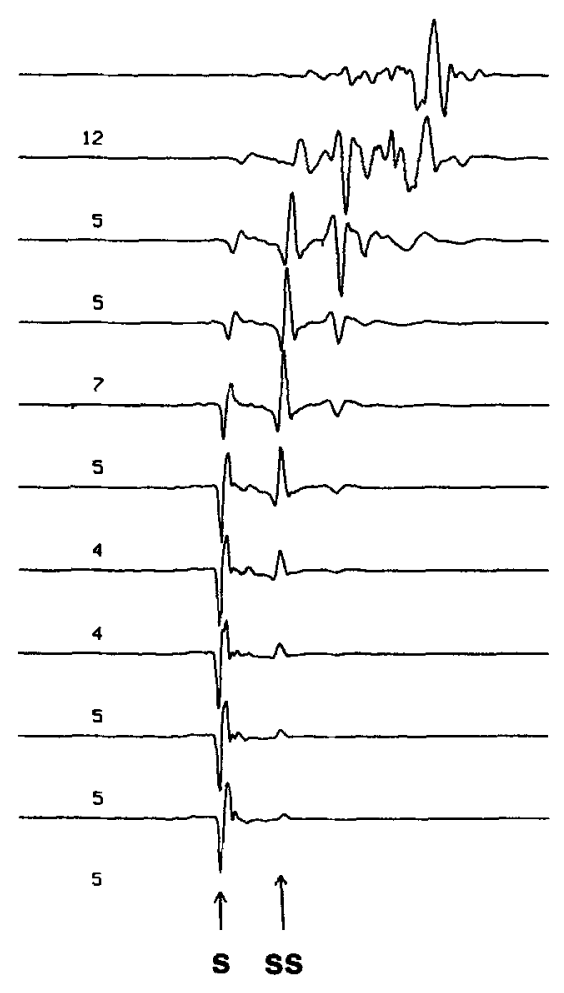

Frg. 4. Example of discrete wavenumber/finite element (DWFE) methodology subfault Green's functions used by WEA. Depth section if for station WST at a distance of $20 \mathrm{~km}$. Subfault numbers 21 to 30 refer to the third column of subfaults in the WEA model parameterization. For the location of these subfaults, the $90^{\circ}$ component is approximately SV and the $180^{\circ}$ component is approximately SH.

the majority of slip is forced closer to the point of rupture nucleation along the deep, northwest portion of the fault." So a 0.5 -sec change in the delay time for subevent 3 changes the slip distribution from the preferred WEA model (307) to one with slip dominated on the northwest part of the fault, similar to the model of F\&W. The added delay naturally forces slip towards the northwest, so there is a trade-off between the timing of the initiation of subevent 3 and the resulting dislocation concentration. This is most unfortunate, as the answers to several key questions concerning the fault dynamics depend on whether significant rupture traversed the fault step-over or whether it acted as a barrier to a majority of the high-frequency radiation. But this may not be clearly resolvable since the position and timing of the subevent nucleation is uncertain.

However, with the added delay, the overall waveform fits were judged to be inferior to those from model 307 based on both visual inspection of the waveforms (see WEA, Fig. 9), and from the formal misfit, the Euclidean norm of the residual vector $(\|\mathbf{b}-\mathbf{A x}\|)$. The model 307, with slip to the southeast, was 
judged to be superior. That model 307 was much more consistent with the results of all the longer-period observations also played a role in the WEA preference of that model. In actuality, as already described by WEA, the waveforms were only moderately improved with the increased amount of slip southeastward in model 307. As a new test, we ran an inversion allowing additional freedom for the initiation time of subevent 3 by increasing the time separation of the three time windows of model 307 to $1.0 \mathrm{sec}$ (rather than 0.5 sec in WEA), effectively letting subevent 3 rupture occur at any time during the time enclosed by the three models in Figure 5. Hence we allowed the inversion to choose between the northwest or southeast slip concentrations. The resulting solution was still that of model 307.

As a further test, we set up our inversion to be more similar to that of F\&W by limiting the stations and components to the subset used by F\&W (with the exception of Octotillo Wells, a distant station with poor signal-to-noise ratio) and by constraining the subevent 3 delay time to be $9.1 \mathrm{sec}$. The results are compared with the original WEA model and are shown in Figure 6 . Below both models we show station observations and synthetics at stations most effected by slip concentrated in the northwest portion of the fault. Waveforms at stations POE and KRN are no longer adequately fit and SSM is less acceptable. At WST, although the component $180^{\circ}$ waveform fit is better with the $\mathrm{F} \& \mathrm{~W}$ model, the amplitude is down by a factor of 2 . It is imperative to note that the timing of the $90^{\circ}$ component at WST is still not matched, even with more slip concentrated in the northwest. This implies that the timing discrepancy noted by Frankel (1992) is not simply resolved by moving slip to the northwest. Although the relative timing is closely tied to the location of the slip, lateral heterogeneities not in the Green's functions are playing a role and are only completely compensated for with extra temporal flexibility allowed in the F\&W tomographic backprojection.

Frankel (1992) states that the consistent timing between subevents 2 and 3 at stations with varying azimuths supports the conclusions of $F \& W$ that that energy is from the northwest portion of the fault. True, and the initial part of subevent 3 does arrive from the northwest portion of the fault in both the F\&W and WEA models. But subevent 3 has a substantial duration at all stations other than PTS and ELC (Fig. 7). These two stations show concentrated, short-duration shear-wave arrivals resulting from rupture directivity. According to the WEA model, this later energy comes from regions further southeast along the fault. In the F\&W model, the 5- or 6 -sec duration of subevent 3 is generated partly from energy beyond the step-over as in WEA, and partly from later energy contributed from the northern part of the fault (Fig. 2). Note, as we have shown in Figure 2, that the duration of slip in the F\&W model from about 0 to $8 \mathrm{~km}$ is several seconds. Near the hypocenter, the F\&W model shows positive and negative slip for about 6 seconds; slip lasts nearly $5 \mathrm{sec}$ out to a distance of at least $10 \mathrm{~km}$ from the hypocenter.

The author's description of the lag in the WEA synthetics at some stations normal to the fault strike is well noted. But there is always a trade-off in such an inversion between fitting the peak waveforms on each record and fitting the exact timing. Again, we do not find these lags very surprising. The true velocity structure is not laterally homogeneous, and the inversion must come up with the best overall fit to the all the records given the assumed velocity structure. We believe that the WEA 1-D, full waveform Green's functions are only a rough 

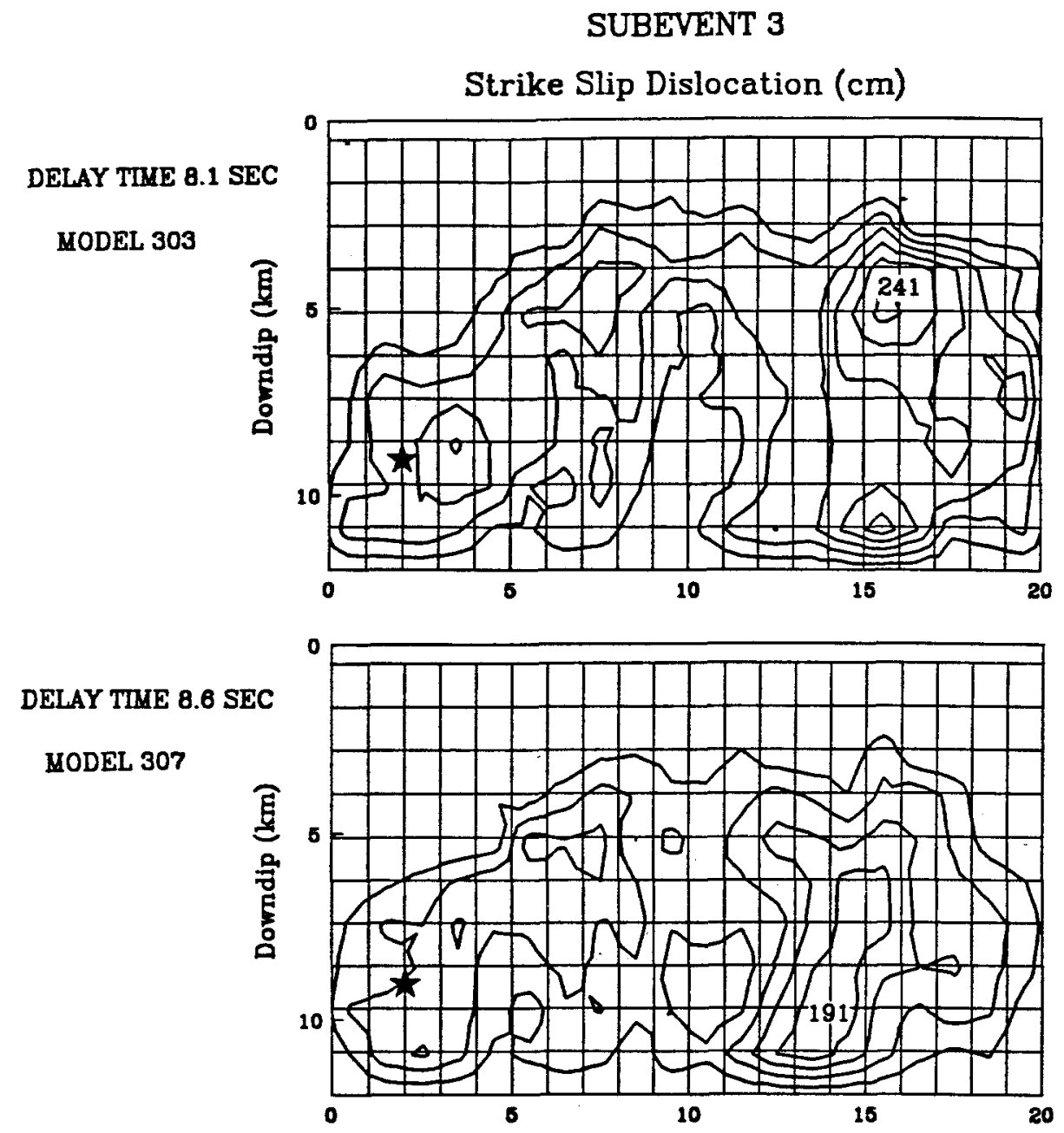

DELAY TIME 9.1 SEC

MODEL 312

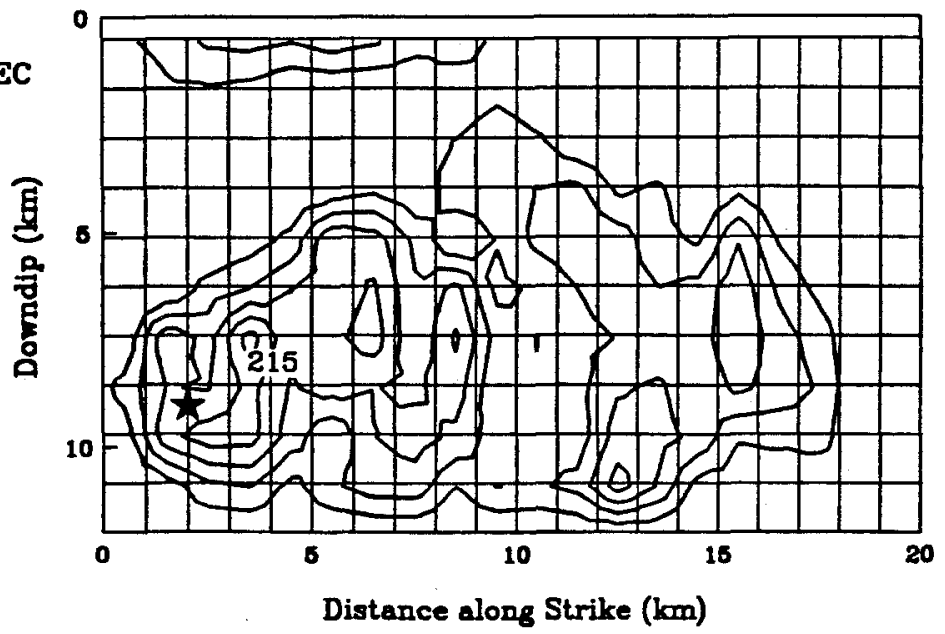

FIG. 5. Comparison of subevent 3 dislocation models for delay times of 8.1 sec (top, model 303), $8.6 \mathrm{sec}$ ( middle, model 307) and $9.1 \mathrm{sec}$ (bottom, model 312). The peak slip values are indicated.
Same as WEA Figure 8 . 
WEA Model 307, 8.6 Sec Delay

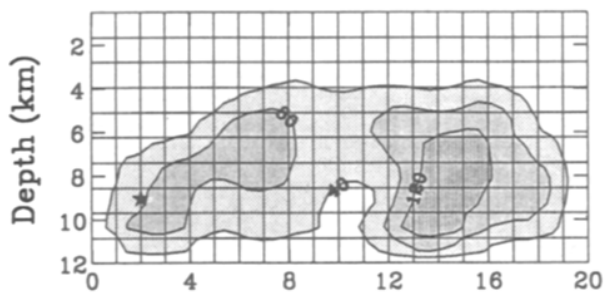

F\&W Stations, 9.1 Sec Delay

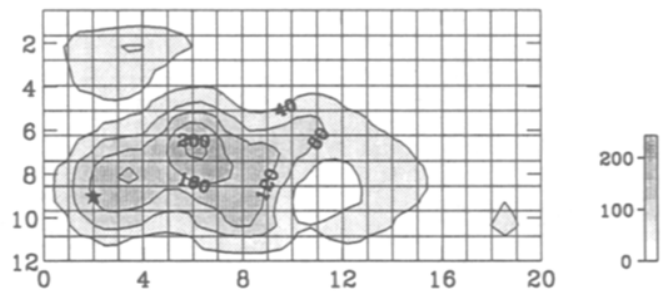

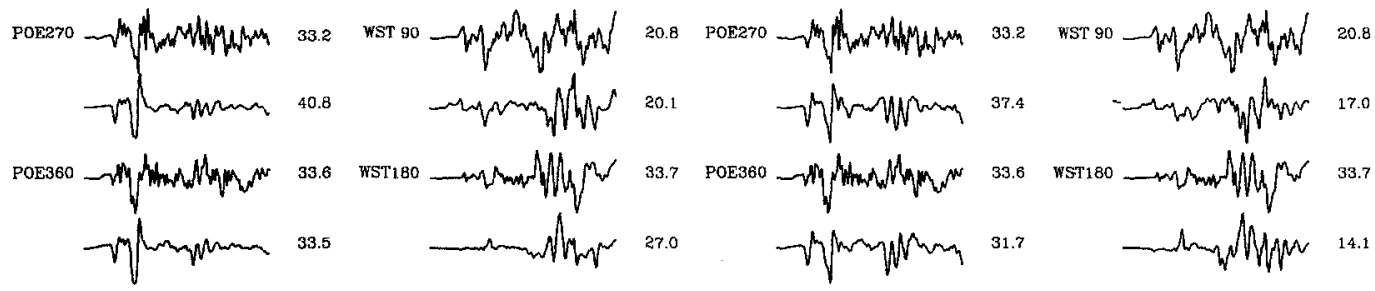

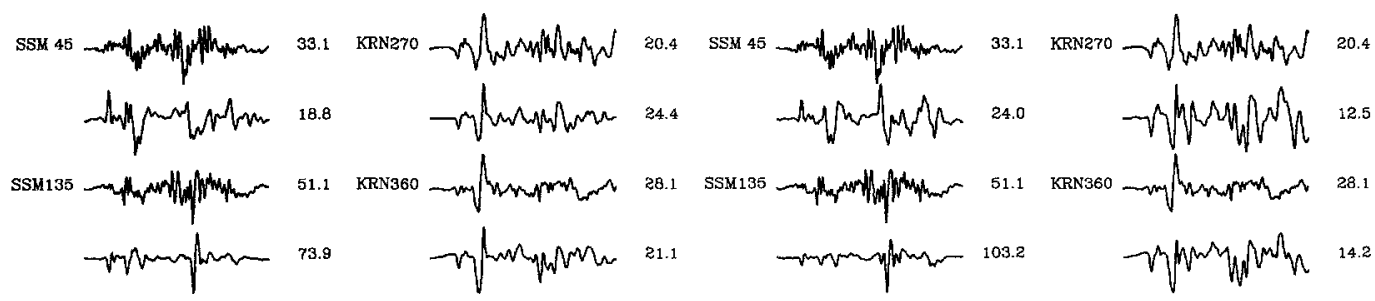

Fig. 6. Subevent 3 slip distribution for the original WEA model 307 (left) and a model similar to F\&W resulting from an inversion using their stations and components (right). Shown below each model are the corresponding waveforms with observations (top) above synthetics (bottom) for each component.

approximation of the likely complex structure in this region. This timing problem is not apparent in the F\&W synthetics, since they can easily compensate for inadequate Green's functions (delta functions) using a sufficiently large number of free parameters. F\&W employ 10,000 unknowns, whereas the number used by WEA is 800 . As described below, we have no difficulty matching the observed timing when we allow some of the flexibility permitted in the F\&W methodology.

The WEA inversion also trades off on the timing of the first arrivals of subevent 3 to ensure a waveform fit to the later, larger, and longer-period arrivals. This longer-period agreement may represent the difference between our results and $F \& W$ 's in that we agree in overall moment and spatial distribution with the longer-period teleseismic studies. The model of F\&W gives a moment a factor of 4 to 5 lower than the teleseismic moment and has less slip on the southern half of the fault plane. The WEA model gives a moment closer to the teleseismic value (less than a factor of 2 smaller) and has more slip southeast of the step-over on the southern segment of the fault. Note, however, that the $F \& W$ moment estimates are calculated for a subjective choice of both rupture length $(0$ to $8 \mathrm{~km})$ and time window $(2 \mathrm{sec})$, missing a substantial amount of moment release that is shown in their Figure 10 and used to compute the synthetics displayed in their Figure 11. 
Tangential Velocities

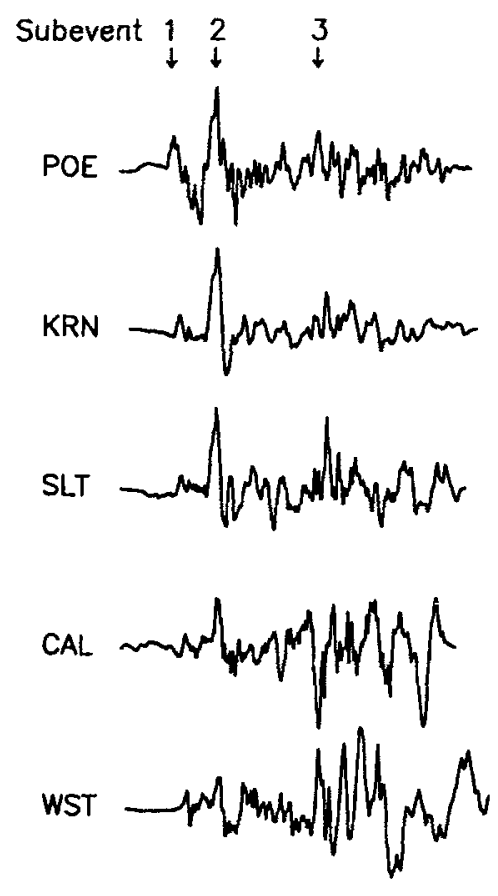

$43.4 \mathrm{~cm} / \mathrm{sec}$

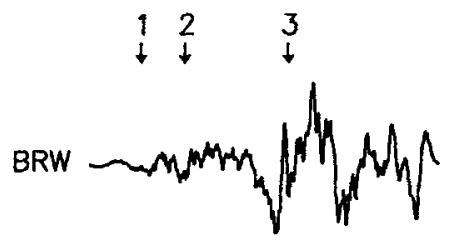

14.1
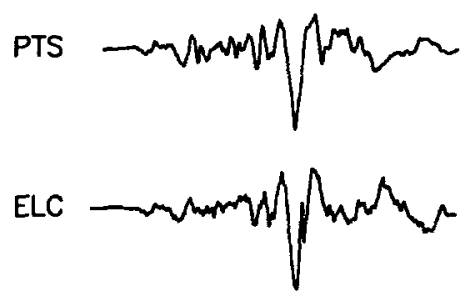

51.6

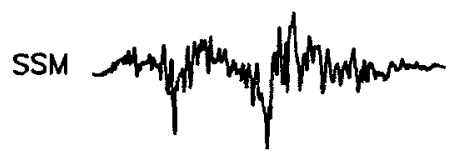

43.6

31.6
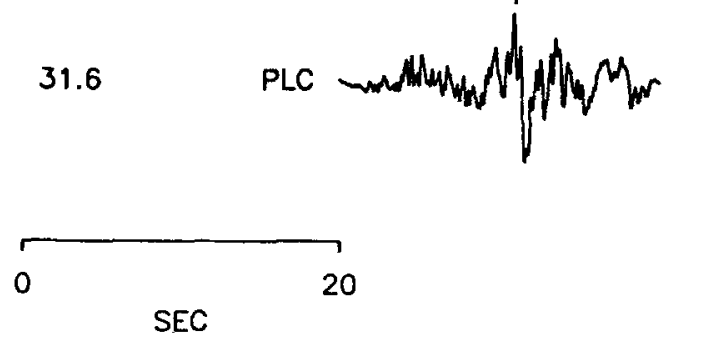

FIG. 7. Tangential velocity recordings of the Superstition Hills earthquake obtained by rotating horizontal components to the backazimuth of the epicenter. Arrows indicate the approximate times of the three subevents. All traces are normalized to their peak value and are aligned vertically by the peak arrival of subevent 2.

Frankel (1992) notes that WEA did not use the Plaster City (PLA) station and that that station is important for constraining the rupture due to its geometry and the impulsive nature of the waveform. Conversely, F\&W do not use two additional near-source stations (BRW and KRN) used by WEA. Further, F\&W use only a single component from each station: the one they judged to be closest to $S H$ motion (with respect to the epicenter). In all, WEA use 14 horizontal components compared to nine components used by $F \& W$. In inversion runs subsequent to the WEA paper we have added station PLC (F\&W's station PLA), and it does not change our conclusions. In fact, we find that the constraints provided by station PLA are not so critical compared to the importance of using both horizontal components from each station. The use of both components at individual stations ensures that proper relative weighting of the effects due to source radiation pattern are differentiated from a simple station site amplification. More important, however, both the WEA and F\&W models require a subevent 3 source length large enough to make the use of a single component highly inadequate; one component that is approximately tangential to the point of rupture initiation can be radial to energy radiated further down the fault. 
Each component has a nontrivial combination of $S H$ and $S V$ energy from the finite fault that can only be correctly modeled with the use of both components. The danger of using only one horizontal component is further compounded by the additional complexity of the Green's functions for the $S V$ component compared with the $S H$ component. (see Green's function, Fig. 4). Frankel (1992) criticizes the WEA waveform fit on the $45^{\circ}$ component for SSM, yet F\&W do not even use this component.

Frankel suggests that station PTS causes the WEA inversion to place slip for subevent 3 closer to PTS than really occurred. This statement was tested by removing PTS from the inversion data set. The result of this test is shown in Figure 8. The removal of PTS from the inversion had a negligible effect and results in a final slip model (Fig. 8, bottom) with the same features as the original model presented in WEA (Fig. 8, top). This result might have been anticipated as only one component was used from station PTS in the WEA

\section{NW Subevent 3 (original Model) SE}

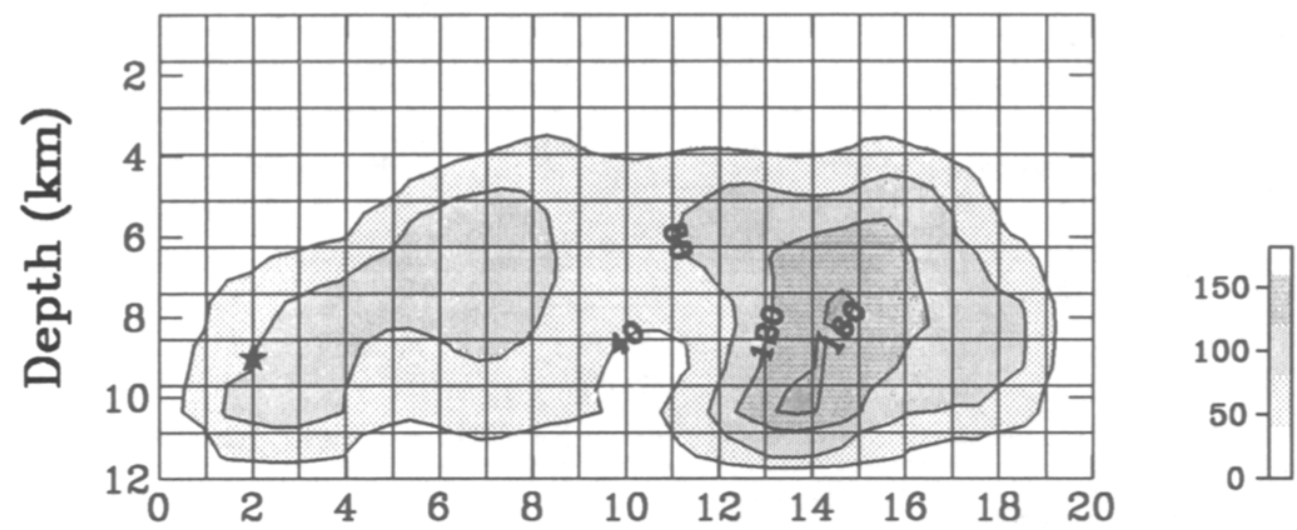

\section{NW Subevent 3 (PTS removed) SE}

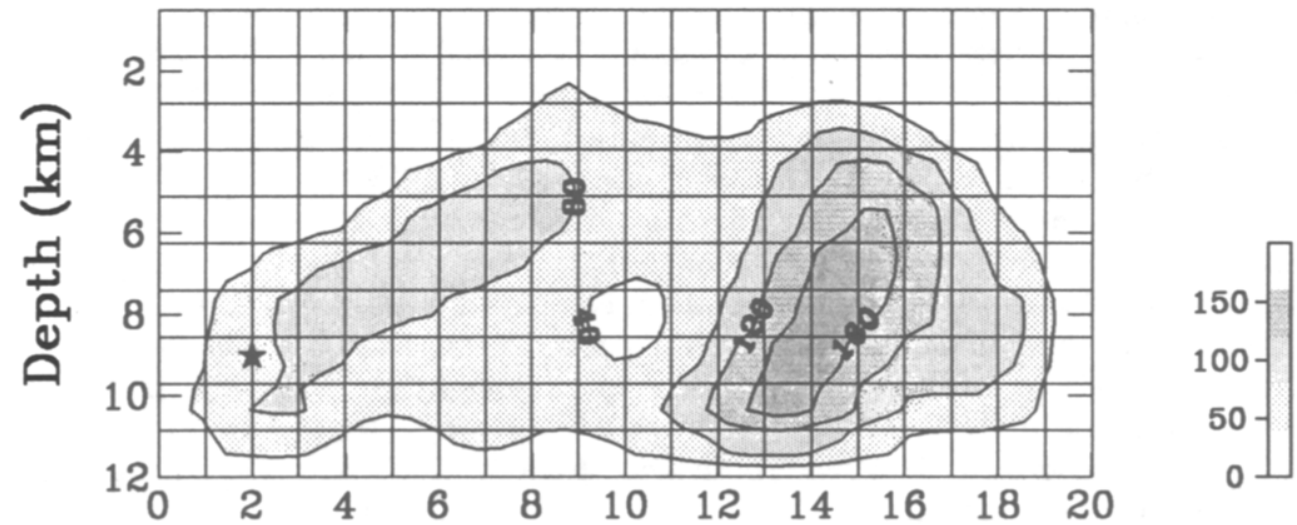

FIG. 8. Comparison of subevent 3 slip distribution with station PTS weighted equally (top) and with PTS given no weight (bottom) in the inversion. 
modeling, compared to two components for most other stations. WEA chose not to use the radial component of PTS $\left(225^{\circ}\right)$, as it is nearly nodal to the fault surface projection and is thus overly sensitive to the assumed fault location. Moreover, each component of data is normalized to unit amplitude prior to the inversion so that each record has equal weight. Without this normalization, the least-squares inversion would tend to fit the larger amplitude records (i.e., PTS) at the expense of smaller amplitude, usually more distant, stations. Of course, the removal of PTS from the inversion is ignoring a valuable recording and was done only as a test of its control on our inversion results.

When comparing models, we became concerned with the possible effects of different model parameterization of $\mathrm{F} \& \mathrm{~W}$ compared to WEA. An advantage of the tomographic source inversion technique used by $F \& W$ over the finite fault inversion scheme used by WEA is that it requires no a priori assumption about each subevent initiation location, rupture time, and rupture velocity. The results of F\&W were very useful as a starting point for the WEA modeling. But the sacrifice for this advantage is the use of delta functions to represent Green's functions and approximating the fault rupture area with a single line source at a chosen depth. In our approach, we must examine this parameter space in an iterative sense, re-running the inversion for each parameter variation. Since this is extremely time consuming, we can only test some of the wide range of possible parameters. The multiple subevent nature of this earthquake certainly aggravates this condition. In this sense, there may well be a better set of $a$ priori model parameters we missed that would provide an enhanced image of the rupture process. Another difference in the modeling techniques is that the tomographic inversion has no constraints on the rupture process. Slip can occur many times and for any duration at a given point and can have arbitrary variations in the amount of slip at adjacent points along the line source. The method used by WEA, originally developed by Hartzell and Heaton (1983), requires rupture to propagate outward from a point at a rupture velocity that is a constant fraction of the local shear velocity. It also has smoothing constraints to minimize the difference in slip between adjacent subfaults.

To best approximate the parameterization used by F\&W, we modified our model in the following manner. First, we employed only the row of subfaults comparable to the 9-km line source depth of F\&W (eighth row, top of Fig. 3). Rupture on these subfaults was allowed during any time covering 30 time windows, each $0.5 \mathrm{sec}$ apart, and no smoothing was applied to minimize slip differences on adjacent subfaults. Because of computational limitations, when using complete Green's functions we were required to limit the number of unknowns to 30 time windows for each of 20 subfaults. Again we employ far fewer unknowns than the 200 time steps at each of 50 line source locations used by $\mathrm{F} \& \mathrm{~W}$. The results of our "line source" inversion are shown in Figure 9 as relative slip contours with a format similar to F\&W's Figure 10. Slip is very similar to that of the 2-D preferred model 307, having substantial slip on both northwest and southeast segments of the fault. Although the overall slip distribution did not change significantly, the additional freedom for numerous ruptures over extended time durations on each subfault allows us to match the timing on the records (Fig. 10), which previously were delayed as described by Frankel (1992).

Finally, let us consider the interesting "speculative scenario" advanced by Frankel (1992) to reconcile the F\&W solution with the longer-period (surface 


\section{Line Source (30 Time Windows) Slip Contours}

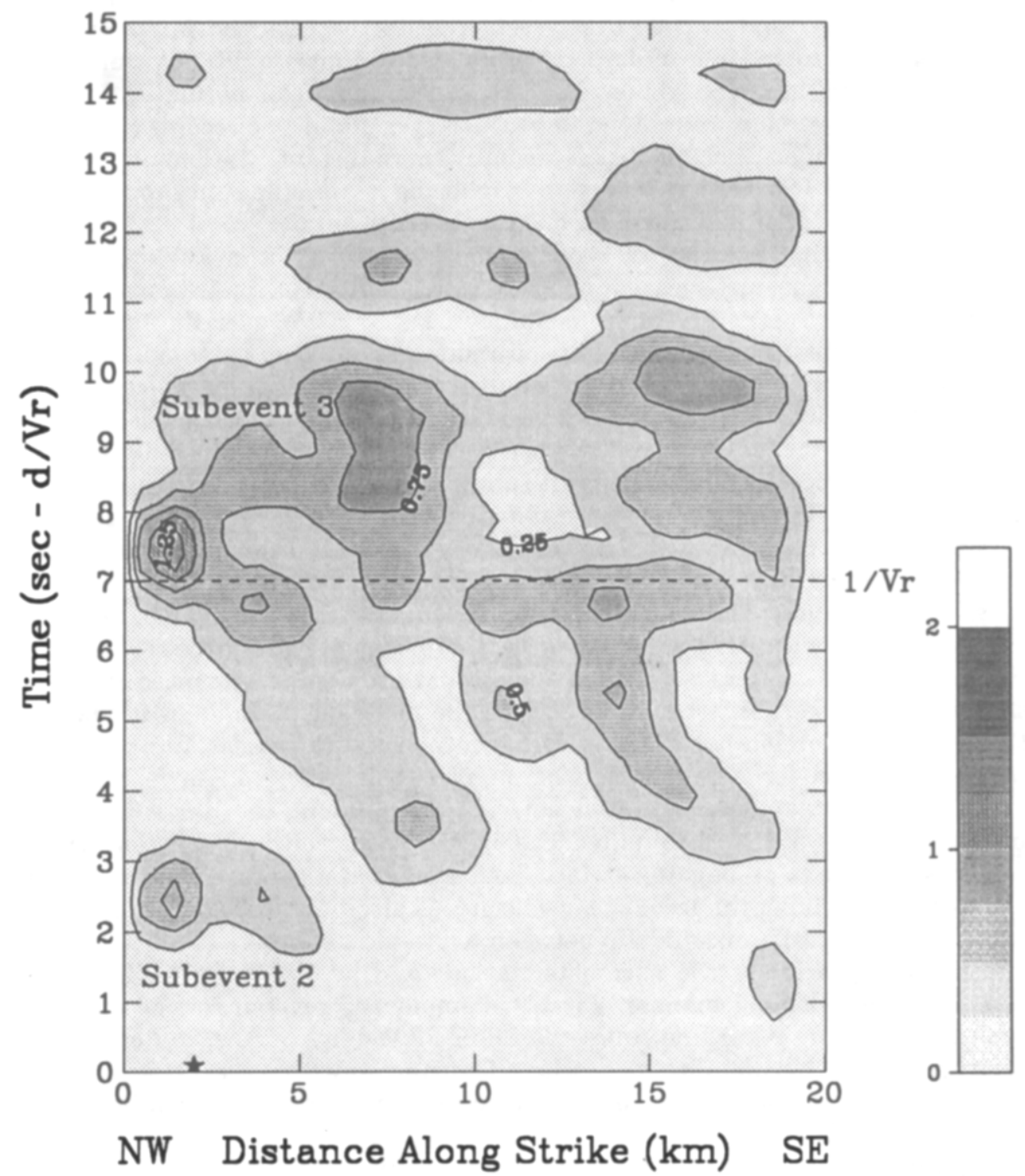

FIG. 9. Line source inversion results showing contours of relative slip. Subevent 3 has significant slip on the southern portion of the fault.

offset, teleseismic, and geodetic) observations. We agree that subevent 2 radiated both high frequencies and long periods from the northern portion of the fault and was therefore seen both locally and teleseismically. However, in order to be consistent with the longer-period observations, Frankel (1992) suggests that the larger subevent 3 , starting $7 \mathrm{sec}$ later, radiated only high frequencies "since slip on the weaker part of the fault was already released by subevent $2 . "$ Then, the high-frequency rupture from subevent 3 in the northwest triggered 

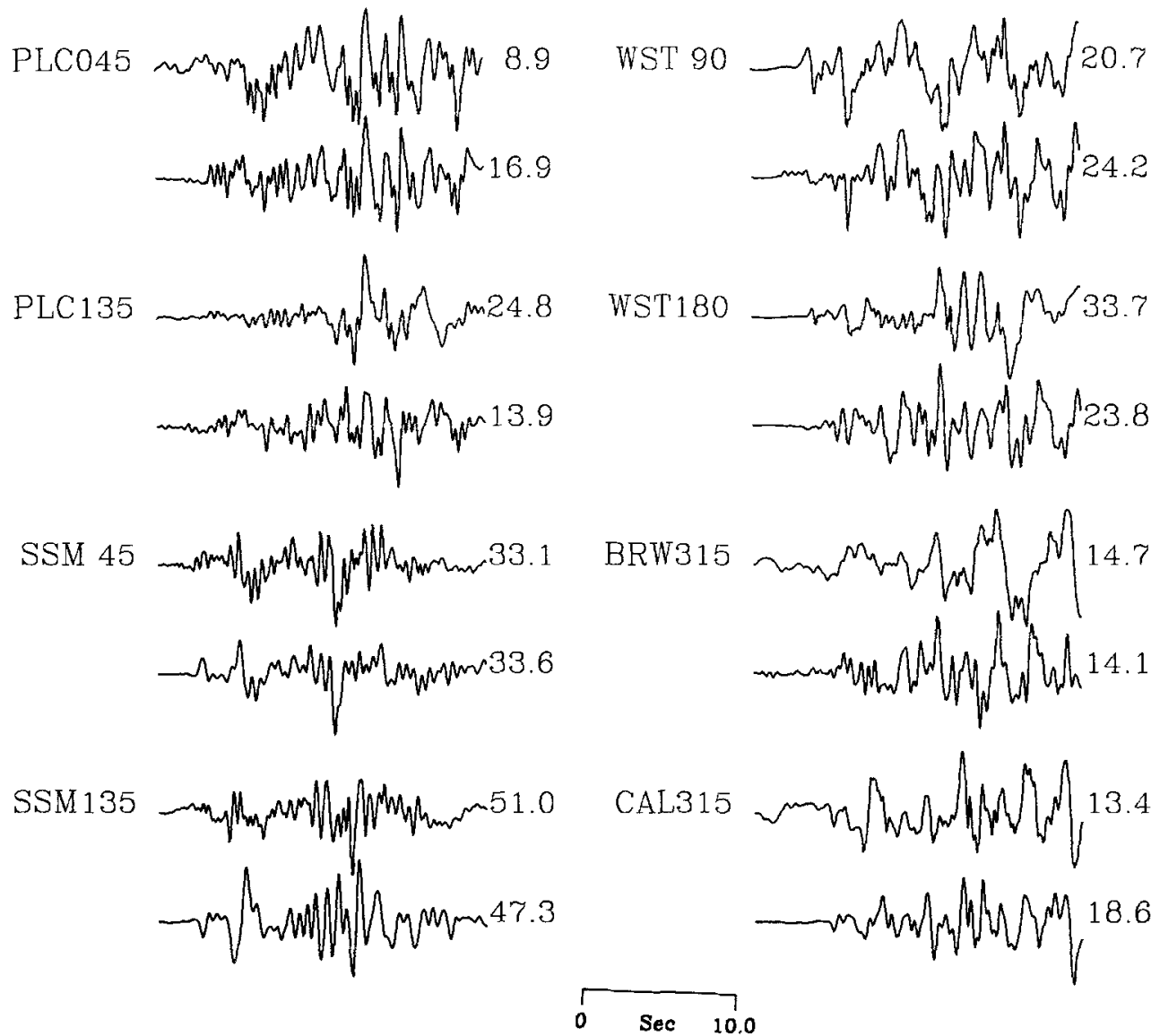

FIG. 10. Observed (top) and synthetic (bottom) seismograms resulting from line source model. Note that the overall timing is well matched.

long-period slip on the southern half of the fault, which was seen teleseismically, yet radiated insufficient high frequencies to be observed at local strongmotion stations. Hence, the northern half of the fault radiated high frequencies without generating long periods and the southern half of the fault conspired to generate long periods while not producing significant high frequencies. But, in fact, the solution of F\&W has long-period slip on the northern half of the fault. As we have shown in Figure 2, the F\&W model has slip durations of several seconds in the northwest. Near the hypocenter the F\&W model shows positive and negative slip for about $6 \mathrm{sec}$; slip lasts nearly $5 \mathrm{sec}$ out to a distance of at least $10 \mathrm{~km}$ from the hypocenter. This implies long-period radiation from the northwest portion of the fault during subevent 3 , which should have been apparent on the teleseismic data considering that its moment was 4 times greater than that of subevent 2 (which was seen). In short, we believe that significant source contributions from other regions of the fault are being mapped into the northwestern portion of the line source with an extended duration of slip.

We do agree that it is possible that different portions of a given fault can have 
frequency-dependent radiation and can therefore look unrelated as viewed by frequency band-limited observations, as Frankel (1992) suggests. For the Superstition Hills earthquake, however, we do not think that high-frequency strong ground motion data require the amount of decoupling from the longer-period observations as suggested by Frankel (1992). As stated in WEA, "the agreement between the longer-period teleseismic models, our strong-motion modeling results, and the afterslip at the surface favors moment release along the southern portion of the Superstition Hills fault radiating both short (1-sec) and long-period (20-sec) energy."

Although the issue addressed here involves the third and largest subevent of the Superstition Hills earthquake, whether one favors the model presented by F\&W or that of WEA, both studies concur that there was significant slip in the same region for three subevents or episodes of slip, separated in time by only a few seconds. Being able to clearly resolve the re-rupturing of one portion of the fault three times makes this a very noteworthy earthquake. An alternative to repeated rupturing requires that subevent 2 ruptured toward the northeast, followed several seconds later by subevent 3 rupturing towards the southeast. We have tested this hypothesis as have $F \& W$ and found that subevent 2 appears compact enough to make resolution of this detail difficult and inconclusive.

There remain discrepancies between the WEA and F\&W models for subevent 3. The simplifications in the F\&W model and waveform misfits in the WEA model warrant attention. Both WEA and F\&W suggest the use of more adequate Green's functions (varying with station location) to reduce the amount of propagation error that is mapped back into source. A good set of aftershock recordings is now available at many of the strong-motion sites employed in these studies, so a useful undertaking might be to develop more adequate theoretical Green's functions for each station or to employ empirical Green's functions in their place.

\section{REFERENCES}

Bent, A. L., D. V. Helmberger, R. J. Stead, and P. Ho-Liu (1989). Waveform modeling of the November 1987 Superstition Hills earthquake, Bull. Seism. Soc. Am. 79, 500-514.

Frankel, A. (1992). Comment on "Rupture process of the 1987 Superstition Hills earthquake from the inversion of strong motion data" by Wald et al., Bull. Seism. Soc. Am. 82, xx-xx.

Frankel, A. and L. Wennerberg (1989). Rupture process of the $M_{S} 6.6$ Superstition Hills earthquake determined from strong-motion recordings: application of tomographic source inversion, Bull. Seism. Soc. Am. 79, 515-541.

Hartzell, S. H. and T. H. Heaton (1983). Inversion of strong ground motion and teleseismic waveform data for the fault rupture history of the 1979 Imperial Valley, California earthquake, Bull. Seism. Soc. Am. 73, 1553-1583.

Hwang, L. J., H. Magistrale, and H. Kanamori (1990). Teleseismic source parameters and rupture characteristics of the 24 November 1987, Superstition Hills earthquake, Bull. Seism. Soc. Am. $80,23-42$.

Larson, S. C. (1991). Geodetic measurement of deformation in southern California, Ph.D. Thesis, California Institute of Technology, Pasadena, $351 \mathrm{pp}$.

Magistrale, H., L. Jones, and H. Kanamori (1989). The Superstition Hills, California, earthquakes of 24 November 1987, Bull. Seism. Soc. Am. 79, 239-251.

Sharp, R. V., K. E. Budding, J. Boatwright, M. J. Ader, M. G. Bonilla, M. M. Clark, T. E. Fumal, K. K. Harms, J. J. Lienkaemper, D. M. Morton, B. J. O'Neill, C. L. Ostergren, D. J. Ponti, M. J. Rymer, J. L. Saxton, and J. D. Sims (1989). Surface faulting along the Superstition Hills fault zone and nearby faults associated with the earthquakes of 24 November 1987, Bull. Seism. Soc. Am. 79, 252-281. 
Wald, D. J., S. H. Hartzell, and D. V. Helmberger (1990). Rupture process of the 1987 Superstition Hills earthquake from the inversion of strong-motion data, Bull. Seism. Soc. Am. 80, 1079-1098.

Williams, P. L. and H. W. Magistrale (1989). Slip along the Superstition Hills fault associated with the 24 November 1987 Superstition Hills, California, earthquake, Bull. Seism. Soc. Am. 79, $390-410$

Seismological Laboratory

California Institute of Technology

Pasadena, California 91125

(D.J.W., D.V.H.)

Manuscript received 24 October 1991
U.S. Geological Survey MS 966, Box 25046

Denver, Colorado 80225 (S.H.H.) 